\title{
Interaction of Dicaproyl Phosphatidylserine With Recombinant Factor VIII and Its Impact on Immunogenicity
}

Submitted: September 22, 2005; Accepted: March 30, 2006; Published: May 26, 2006

Vivek S. Purohit ${ }^{1,2}$ and Sathyamangalam V. Balasubramanian ${ }^{1}$

${ }^{1}$ Department of Pharmaceutical Sciences, University at Buffalo, State University of New York, Amherst, NY 14260-1200

${ }^{2}$ Current address: Eurand, Inc, 845 Center Drive, Vandalia, OH 45377

\section{ABSTRACT}

Replacement therapy with exogenous recombinant factor VIII (rFVIII) to control bleeding episodes results in the development of inhibitory antibodies in $15 \%$ to $30 \%$ of hemophilia A patients. The inhibitory antibodies are mainly directed against specific and universal immunodominant epitopes located in the C2 domain. Previously we have shown that complexation of O-phospho-L-serine (phosphatidylserine head group) with the phospholipid binding region of the $\mathrm{C} 2$ domain can lead to an overall reduction in the immunogenicity of rFVIII. Here, we have investigated the hypothesis that dicaproyl phosphatidylserine, a shortchain water-soluble phospholipid, can reduce the immunogenicity of rFVIII. Circular dichroism and fluorescence spectroscopy studies suggest that dicaproyl phosphatidylserine interacts with rFVIII, causing subtle changes in the tertiary and secondary structure of the protein. Sandwich enzyme-linked immunosorbent assay studies indicate that dicaproyl phosphatidylserine probably interacts with the phospholipid binding region of the $\mathrm{C} 2$ domain. The immunogenicity of FVIII-dicaproyl phosphatidylserine complexes prepared at concentrations above and below the critical micellar concentrations of the lipid were evaluated in hemophilia A mice. Our results suggest that micellar dicaproyl phosphatidylserine may be useful to reduce the immunogenicity of rFVIII preparations.

KEYWORDS: Hemophilia A, inhibitor development, aggregation, recombinant human factor VIII, protein folding, factor VIII-DCPS complex

\section{INTRODUCTION}

Factor VIII (FVIII) is a multidomain glycoprotein that comprises 6 main domains: $\mathrm{NH}_{2}-\mathrm{A} 1-\mathrm{A} 2-\mathrm{B}-\mathrm{A} 3-\mathrm{C} 1-\mathrm{C} 2-\mathrm{COOH} .{ }^{1}$ The protein is synthesized mainly in the liver cells as a 2351

Corresponding Author: Sathyamangalam V.

Balasubramanian, Department of Pharmaceutical

Sciences, 527 Hochstetter Hall, University at Buffalo, State University of New York, Amherst, NY 14260-1200. Tel: (716) 645-2842 ext 245; Fax: (716) 645-3693; E-mail: svb@acsu.buffalo.edu residue single-chain precursor protein. ${ }^{2}$ Prior to secretion, the protein is proteolytically processed to form the heavy chain (A1-A2-B) having a molecular weight of 90 to 180 $\mathrm{kDa}$ and the light chain (A3-C1-C2) having a molecular weight of $\sim 80 \mathrm{kDa}^{3-5}$ The heavy and the light chains are held together by a divalent calcium ion. ${ }^{6}$ The protein circulates in the plasma as a complex with von Willebrand factor. $^{7-9}$

Hemophilia A is a life-threatening bleeding disorder caused by deficiency or dysfunction of FVIII. ${ }^{10}$ Hemophilia A patients usually experience spontaneous bleeding that can be controlled only by the exogenous administration of FVIII preparations. ${ }^{11}$ Currently, replacement therapy with recombinant FVIII (rFVIII) preparations is the treatment of choice for controlling the bleeding episodes. However, replacement therapy with rFVIII preparations leads to the development of inhibitory antibodies in $15 \%$ to $30 \%$ of patients. ${ }^{12}$ The pathophysiology of inhibitor development is not completely understood, with genetic and product-related factors being implicated as contributors to the development of inhibitors. ${ }^{13,14}$ Development of inhibitors complicates replacement therapy with rFVIII preparations, necessitating more frequent and higher doses to control the bleeding episodes. Alternative treatment strategies such as bypass therapy with factor $\mathrm{VIIa}^{15}$ or porcine FVIII, ${ }^{16}$ and immune tolerance therapy with high doses of $\mathrm{rFVIII},{ }^{17}$ have been used to manage patients with inhibitors. However, these alternatives are not successful in all patients and significantly increase the cost of therapy. Hence, rFVIII preparations that prevent the development of inhibitors are desirable.

The main immunodominant epitopes of rFVIII have been found to be located in the $\mathrm{C} 2, \mathrm{~A} 3$, and $\mathrm{A} 2$ domains of FVIII. ${ }^{12,18-20}$ Additionally, the $\mathrm{C} 2$ domain region 2291 to 2330 has been shown to encompass several universal immunodominant epitopes for CD4+ T cells. ${ }^{21,22}$ The phospholipid binding region 2303 to 2332 is also located in this area and has structural features of universal immunodominant epitopes. ${ }^{23}$

We have previously shown that O-phospho-L-serine, ${ }^{24}$ the head group of phosphatidylserine and phosphatidylserine-rich liposomes (K. Ramani, V. Purohit. R.M. Straubinger, S.V. Balasubramanian, unpublished data, 2005) capable of binding to the phospholipid binding region, can reduce the immunogenicity of rFVIII in 
hemophilia A mice. Dicaproyl phosphatidylserine (DCPS) is a unique water-soluble lipid that can exist as micelles at concentrations above the critical micellar concentrations (CMCs). Both the soluble and micellar forms of DCPS may interact with rFVIII because of the presence of the phosphoserine head group and influence the immunogenicity of rFVIII. Here, we have investigated the effects of DCPS, a short-chain phosphatidylserine capable of existing in the soluble (monomolecular) as well as micellar (multimolecular assembly) forms, on the immunogenicity of rFVIII in hemophilia A mice. The effects of DCPS on the secondary and tertiary structure of rFVIII were investigated using circular dichroism (CD) and fluorescence spectroscopy, respectively. We confirmed that DCPS can bind to the phospholipid binding region of the $\mathrm{C} 2$ domain of rFVIII using sandwich enzyme-linked immunosorbent assay (ELISA). We have also evaluated the impact of DCPS on the immunogenicity of rFVIII hemophilia A mice. The results suggest that DCPS may be useful in reducing the immunogenicity of rFVIII.

\section{MATERIAls AND METHODS}

\section{Materials}

rFVIII was obtained from Baxter Healthcare (Carlsbad, CA). Monoclonal antibodies ESH4 and ESH8 were obtained from American Diagnostica Inc (Greenwich, CT). Activity assays were performed with normal coagulation control plasma and FVIII-deficient plasma purchased from Trinity Biotech (Co Wicklow, Ireland). Platelin L reagent was purchased from BioMerieux (Durham, NC). The activated partial thromboplastin time (APTT) and Bethesda assay was performed using a COAG-A-MATE coagulation analyzer (Organon Teknika Corporation, Durham, NC). Diethanolamine, tryptophan, and $30 \%$ essentially immunoglobulin-free bovine serum albumin were obtained from Sigma (St Louis, MO). 1,6-Diphenyl-1,3,5-hexatriene was obtained from Molecular Probes (Eugene, OR). p-Nitrophenyl phosphate was purchased from Pierce (Rockford, IL). DCPS and dicaproyl phosphatidylcholine (DCPC) as chloroform solutions were obtained from Avanti Lipids (Alabaster, AL). All buffer salts were purchased from Fisher Scientific (Fair Lawn, NJ) and used without further purification.

\section{Determination of CMC of DCPS}

Lipid films corresponding to various amounts $(5 \mu \mathrm{M}-$ $1 \mu \mathrm{M})$ of DCPS were prepared from a chloroform stock solution by evaporating the solvent in a rota-evaporator. The films were reconstituted with Tris buffer $(5 \mathrm{mM}$ or $1 \mathrm{mM} \mathrm{CaCl}_{2}, 25 \mathrm{mM}$ Tris, and $300 \mathrm{mM} \mathrm{NaCl}, \mathrm{pH}=7$ ) by vortexing to obtain $5,4.5,4,3.5,3,2.5,2$, and $1 \mathrm{mM}$ DCPS solutions. Two $\mu \mathrm{L}$ of a $0.005 \mathrm{M}, 1,6$-diphenyl-2,4,6hexatriene $(\mathrm{DPH})$ solution in tetrahydrofuran was added to the above solutions, incubated at $37^{\circ} \mathrm{C}$ for 30 minutes, and stored in the dark for 1 hour. The fluorescence of the samples was measured in a PTI-Quantamaster fluorescence spectrophotometer (Photon Technology International, Lawrenceville, NJ). Excitation wavelength was set at $360 \mathrm{~nm}$, and emission was monitored at $430 \mathrm{~nm}$. An I-shaped cuvette was used for all fluorescence measurements to minimize any interference due to scattering caused by the presence of micelles. The fluorescence intensities were plotted against the concentration of DCPS, and independent linear regressions were performed on the data above and below the putative CMC. The point of intersection of the 2 independent linear regressions was considered the CMC for DCPS.

\section{Preparation of rFVIII-DCPS Complexes}

rFVIII-DCPS complexes were prepared by diluting a concentrated stock solution of rFVIII in buffer comprising $0.05 \mathrm{mM}$ (below CMC) or $5 \mathrm{mM}$ (above CMC) DCPS in $25 \mathrm{mM}$ Tris, $1 \mathrm{mM} \mathrm{CaCl}_{2}$, and $300 \mathrm{mM} \mathrm{NaCl}, \mathrm{pH} 7.0$. The solution was incubated at room temperature for 30 minutes. rFVIII complexes with DCPC were also prepared as described for rFVIII-DCPS complex by diluting with Tris buffer containing $0.05 \mathrm{mM}$ (below CMC) DCPC. For the immunogenicity studies, the solutions were prepared using pyrogen-free water and were sterile filtered prior to use.

\section{Effect of DCPS on Tertiary Structure of rFVIII}

A stock solution of DCPS at a concentration of $1 \mathrm{mM}$ was prepared in Tris buffer $(25 \mathrm{mM}$ Tris, $300 \mathrm{mM} \mathrm{NaCl}$, and $5 \mathrm{mM}$ $\mathrm{CaCl}_{2}, \mathrm{pH} 7$ ) containing $0.017 \mu \mathrm{M}$ rFVIII. Required volumes of the above solution as calculated by the alligation method were added to a $0.017 \mu \mathrm{M}$ solution of rFVIII in Tris buffer to obtain various concentrations of DCPS. Each addition was followed by an equilibration period of $\sim 5$ minutes before the fluorescence of the sample was measured. The fluorescence measurements of rFVIII in the presence of various concentrations of DCPS were performed using a PTI-Quantamaster fluorescence spectrophotometer (Photon Technology International, Lawrenceville, NJ). Excitation wavelength was set at $285 \mathrm{~nm}$, and fluorescence intensity was monitored at $335 \mathrm{~nm}$ for single wavelength measurements. Emission spectra were obtained over a wavelength range of 300 to $400 \mathrm{~nm}$. The fluorescence intensity (F) at $335 \mathrm{~nm}$ at a given concentration of DCPS was normalized to the fluorescence intensity of $\mathrm{rFVIII}$ $\left(F_{o}\right)$ in the absence of DCPS, to obtain the $\mathrm{F} / \mathrm{F}_{\mathrm{o}}$ ratio. The $\mathrm{F} / \mathrm{F}_{\mathrm{o}}$ ratio relates to $\mathrm{rFVIII}$ and DCPS concentrations by the following equation ${ }^{25}$ : 


$$
\begin{aligned}
\frac{F}{F_{o}}= & 1-\frac{F_{\max } *\left[\left[K_{D}+P_{T}+L_{T}\right]\right.}{P_{T} * 2} \\
& \left.-\sqrt{\left[K_{D}+P_{T}+L_{T}\right]^{2}-4 * P_{T} * L_{T}}\right]
\end{aligned}
$$

where $\mathrm{F}_{\max }=$ maximal change in $\mathrm{F} / \mathrm{F}_{\mathrm{o}}, \mathrm{P}_{\mathrm{T}}=$ total protein concentration, $\mathrm{K}_{\mathrm{D}}=$ binding constant, and $\mathrm{L}_{\mathrm{T}}=$ total ligand concentration.

The data were plotted as $\mathrm{F} / \mathrm{F}_{\mathrm{o}}$ versus DCPS concentration $(\mu \mathrm{M})$ and fitted using WinNonlin (Pharsight, Mountain View, CA) with Equation 1 to obtain estimates for $\mathrm{K}_{\mathrm{D}}$. The above equation assumes a stoichiometry (n) of 1 and a single binding site. Attempts were also made to fit the data to an equation assuming 2 independent binding sites.

\section{Effect of DCPS on Secondary Structure of rFVIII}

The effect of DCPS on the secondary structure of rFVIII was studied in a manner identical to that described above. $\mathrm{rFVIII}$ was used at a concentration of $0.068 \mu \mathrm{M}$, and changes in secondary structure were monitored using far UV CD spectroscopy. CD spectra were acquired using a JASCO715 spectropolarimeter (Jasco, Inc, Easton, MD) calibrated with d-10 camphor sulfonic acid. The spectra were obtained from 208 to $250 \mathrm{~nm}$, and ellipticity was monitored at 215 $\mathrm{nm}$ in a $1-\mathrm{cm}$ quartz cuvette. Furthermore, the CD spectrum of rFVIII was corrected by subtracting the baseline spectrum of the appropriate concentration of DCPS in Tris buffer. The ellipticity (E) at $215 \mathrm{~nm}$ at a given concentration of DCPS was normalized to the ellipticity of $\mathrm{rFVIII}\left(\mathrm{E}_{\mathrm{o}}\right)$ in the absence of DCPS, to obtain the $\mathrm{E} / \mathrm{E}_{\mathrm{o}}$ ratio. The $\mathrm{E} / \mathrm{E}_{\mathrm{o}}$ ratio relates to the $\mathrm{rFVIII}$ and DCPS concentrations by Equation 1. The data were plotted and fitted as described above to estimate $K_{D}$.

\section{Sandwich ELISA-Interaction of DCPS With rFVIII}

Binding of DCPS to the phospholipid binding region of rFVIII was confirmed by evaluating the ability of DCPS to inhibit the binding of rFVIII to ESH4, an antibody that binds to the phospholipid binding region of the $\mathrm{C} 2$ domain. The above was confirmed using the sandwich ELISA protocol described previously. ${ }^{24}$ DCPS was used at concentrations of $0.5,2$, and $5 \mathrm{mM}$. DCPC is a short-chain water-soluble ana$\log$ of phosphatidylcholine that has a CMC of 15 to $20 \mathrm{mM}^{26}$ DCPC was also evaluated for its interaction with the phospholipid binding region, as a control.

\section{Effect of DCPS on Thermal Denaturation of rFVIII}

All studies with DCPS were conducted at concentrations below the CMC. The unfolding of rFVIII upon thermal stress was monitored using CD spectroscopy. CD spectra were acquired on a JASCO-715 spectropolarimeter cali- brated with d-10 camphor sulfonic acid. The protein was subjected to thermal denaturation in the presence and in the absence of $0.05 \mathrm{mM}$ DCPS at a controlled heating rate of $60^{\circ} \mathrm{C} / \mathrm{hr}$ from $20^{\circ} \mathrm{C}$ to $80^{\circ} \mathrm{C}$ and a 2-minute holding time at every $5^{\circ} \mathrm{C}$ increment. Temperature was controlled using a Peltier 300 RTS unit (Jasco, Inc), and the thermal unfolding profiles were generated using software provided by the CD instrument manufacturer. The data were represented as change in ellipticity $(\delta \theta)$ as a function of temperature. $\delta \theta$ was computed as $\theta_{\mathrm{t}}-\theta_{\mathrm{n}}$, where $\theta_{\mathrm{n}}$ is the ellipticity of the protein in the native state obtained by averaging the ellipticities at the initial temperatures, and $\theta_{\mathrm{t}}$ is the ellipticity at a given temperature. The transition temperature $\left(\mathrm{T}_{\mathrm{m}}\right)$ for the unfolding profile was obtained by fitting the data to a sigmoid function (Equation 1) using WinNonlin.

$$
Y_{\text {observed }}=Y_{\text {native }}-\frac{\left(Y_{\text {native }}-Y_{\text {unfolded }}\right) \times T^{Y}}{T^{Y}+T m y}
$$

where $Y_{\text {observed }}$ is the ellipticity at $215 \mathrm{~nm}$ at a given temperature, $\mathrm{Y}_{\text {native }}$ is the ellipticity of the native protein, $\mathrm{Y}_{\text {unfolded }}$ is the ellipticity of the unfolded protein, $\mathrm{T}_{\mathrm{m}}$ is the transition temperature, and $\gamma$ is the fitting function.

Protein concentrations used were $\sim 20 \mu \mathrm{g} / \mathrm{mL}$ in Tris buffer. The spectral changes of the sample were monitored at 215 $\mathrm{nm}$, and the spectra were obtained from 250 to $208 \mathrm{~nm}$ in a 1-cm quartz cuvette. The CD spectrum of rFVIII was corrected by subtracting the baseline spectrum of $0.05 \mathrm{mM}$ DCPS buffer. Higher concentrations of DCPS contributed significantly to the buffer baseline and were not investigated. The above thermal denaturation studies were conducted in Tris buffer because of its low metal ion binding capacity. ${ }^{27}$ Because of the high temperature coefficient of Tris buffer, the observed changes at elevated temperatures could be due to a combination of temperature and $\mathrm{pH}$ changes. However, thermal denaturation of rFVIII was also carried out in morpholinepropane sulfonic acid (MOPS) buffer, which has minimal $\mathrm{pH}$ change at elevated temperatures, and the profiles were comparable to those obtained in Tris. ${ }^{28}$

\section{Animals}

A colony of hemophilia A mice $(\mathrm{C} 57 \mathrm{BL} / 6 \mathrm{~J}$ with a target deletion in exon 16 of the FVIII gene) was established with breeding pairs from the original colony. ${ }^{29}$ Equal numbers of adult male and female mice, aged 8 to 12 weeks, were used for the studies. The sex of the animal has no impact on the immune response. ${ }^{30}$

\section{Immune Response}

Immunization of hemophilia A mice consisted of 4 weekly subcutaneous (sc) injections of rFVIII or rFVIII-DCPS complex. Each dose consisted of $2 \mu \mathrm{g}$ of protein in $100 \mu \mathrm{L}$ 
of Tris buffer. The sc route of immunization was used mainly to amplify the immune response against administered rFVIII. ${ }^{24}$ Blood samples by cardiac puncture were obtained from immunized animals in the acid citrate dextrose buffer at 6 weeks postimmunization. The immunogenicity of rFVIII-DCPC complex was also evaluated as an additional control to evaluate the specificity of observed effects. All studies were performed in accordance with the guidelines of the Institutional Animal Care and Use Committee at the University at Buffalo.

\section{Measurement of Total and Inhibitory Anti-rFVIII Antibody Titers}

Antibody titers were determined by standard antibodycapture ELISA, as described previously. ${ }^{24}$ Inhibitory antibody titers were determined using the Nijmegen modification of the Bethesda (NMB) assay, as described previously. ${ }^{24}$ The inhibitory titers were expressed in terms of Bethesda units (BU); $1 \mathrm{BU}$ is the amount of antibody neutralizing $50 \%$ of FVIII activity under prescribed test conditions. Higher inhibitory titers usually indicate higher concentrations of inhibitory antibodies.

\section{RESULTS AND DISCUSSION}

\section{CMC of DCPS}

The CMC of DCPS was determined by fluorescence spectroscopy using DPH as a hydrophobic probe. ${ }^{31}$ At lipid concentrations below CMC, DPH exists predominantly in an aqueous environment and exhibits low fluorescence. Formation of micelles results in the preferential partitioning of the DPH into the hydrophobic regions of micelles with a concomitant sharp increase in fluorescence. As can be seen in Figure 1, an increase in the concentration of DCPS beyond $2.3 \mathrm{mM}$ (estimated using regression, as described in Materials and Methods) results in a sharp increase in fluorescence intensity, indicating the formation of micelles. At concentrations above $\mathrm{CMC}$, formation of a flocculated precipitate was also observed, possibly because of the interaction of DCPS with $\mathrm{Ca}^{2+}$. This is consistent with the observation that $\mathrm{Ca}^{2+}$ ions interact with phosphatidylserine to form nonlamellar lipidic structures such as chochleates. ${ }^{32,33}$ Reduction in the $\mathrm{Ca}^{2+}$ ion concentration to $1 \mathrm{mM}$ prevented the formation of the precipitate without altering the CMC ( $\sim 2.7 \mathrm{mM})$ of DCPS. Hence, subsequent experiments with DCPS at concentrations above the CMC were conducted in buffer containing $1 \mathrm{mM} \mathrm{CaCl}_{2}$.

\section{Effect of DCPS on Tertiary and Secondary Structure of rFVIII}

The tertiary structural changes of rFVIII were monitored by steady-state fluorescence spectroscopy in the presence and

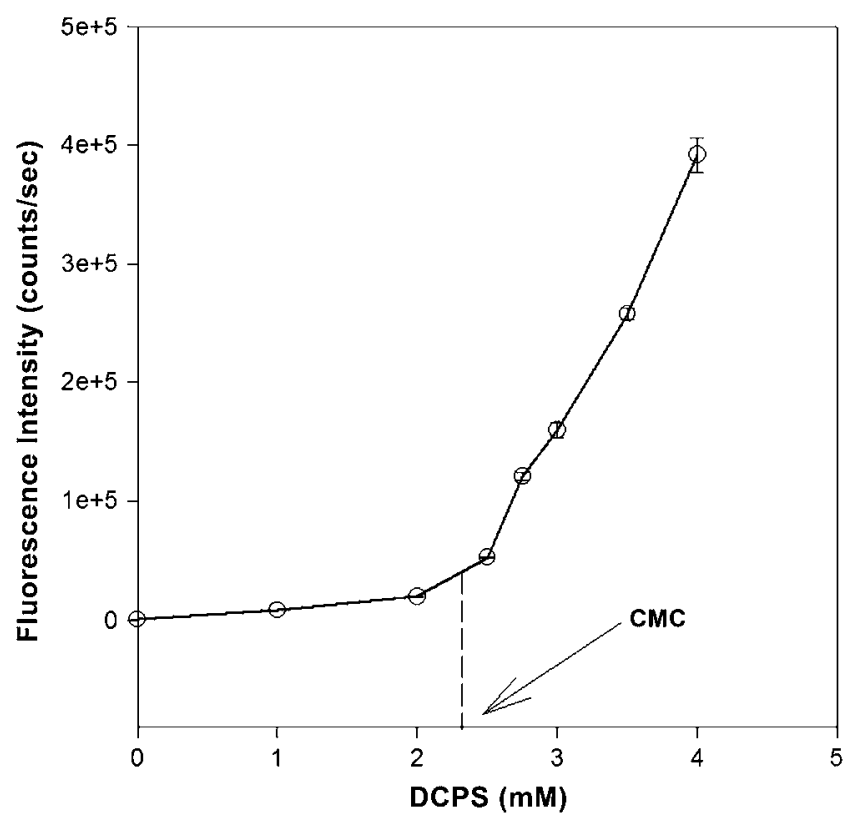

Figure 1. Determination of the critical micellar concentration of DCPS using DPH as a probe. DCPS indicates dicaproyl phosphatidylserine; DPH, 1,6-diphenyl-1,3,5-hexatriene; CMC, critical micellar concentration.

absence of DCPS. As can be seen in Figure 2a, increasing concentrations of DCPS caused a decrease in the intrinsic fluorescence of rFVIII at $335 \mathrm{~nm}$. The decrease in intrinsic fluorescence saturated at a DCPS concentration of $\sim 50 \mu \mathrm{M}$, but this decrease was not accompanied by a shift in the $\lambda_{\max }$ (Figure 2a). The addition of DCPS did not quench the fluorescence of free tryptophan in solution (Figure 2b). The data suggest that DCPS causes subtle changes in the tertiary structure of rFVIII and are consistent with the observation that DCPS causes similar changes in the tertiary structure upon interaction with factor $\mathrm{V}_{\mathrm{a}}{ }^{34}$ The data were appropriately described by Equation 1, which estimated an apparent $\mathrm{K}_{\mathrm{D}}$ of $3.31 \mu \mathrm{M}( \pm \mathrm{SE}, 0.38)$ with a maximal change $\left(\mathrm{F}_{\max }\right)$ of $\sim 32 \%$. The above data further suggest that the interaction of DCPS with rFVIII is similar to its interaction with O-phospho-L-serine (OPLS), as reported earlier. ${ }^{24}$ Hence, the interaction of soluble forms of phosphoserine (DCPS below CMC, and OPLS) is mainly mediated by the phosphoserine moiety, with very little contribution from the lipid component of the molecule.

The effect of DCPS on the secondary structure of rFVIII was monitored using far UV CD spectroscopy. Because we were unable to scan the far UV CD spectra beyond $205 \mathrm{~nm}$ (because of buffer interference), the exact effect of DCPS on the secondary structural elements ( $\alpha$-helix, $\beta$-sheet, etc) of rFVIII could not be ascertained unambiguously. However, structural changes were determined by monitoring the changes in ellipticity at $215 \mathrm{~nm}$ in the presence and absence of DCPS. Increasing concentrations of DCPS caused a slight decrease in the negative ellipticity; this suggests 
The AAPS Journal 2006; 8 (2) Article 41 (http://www.aapsj.org).
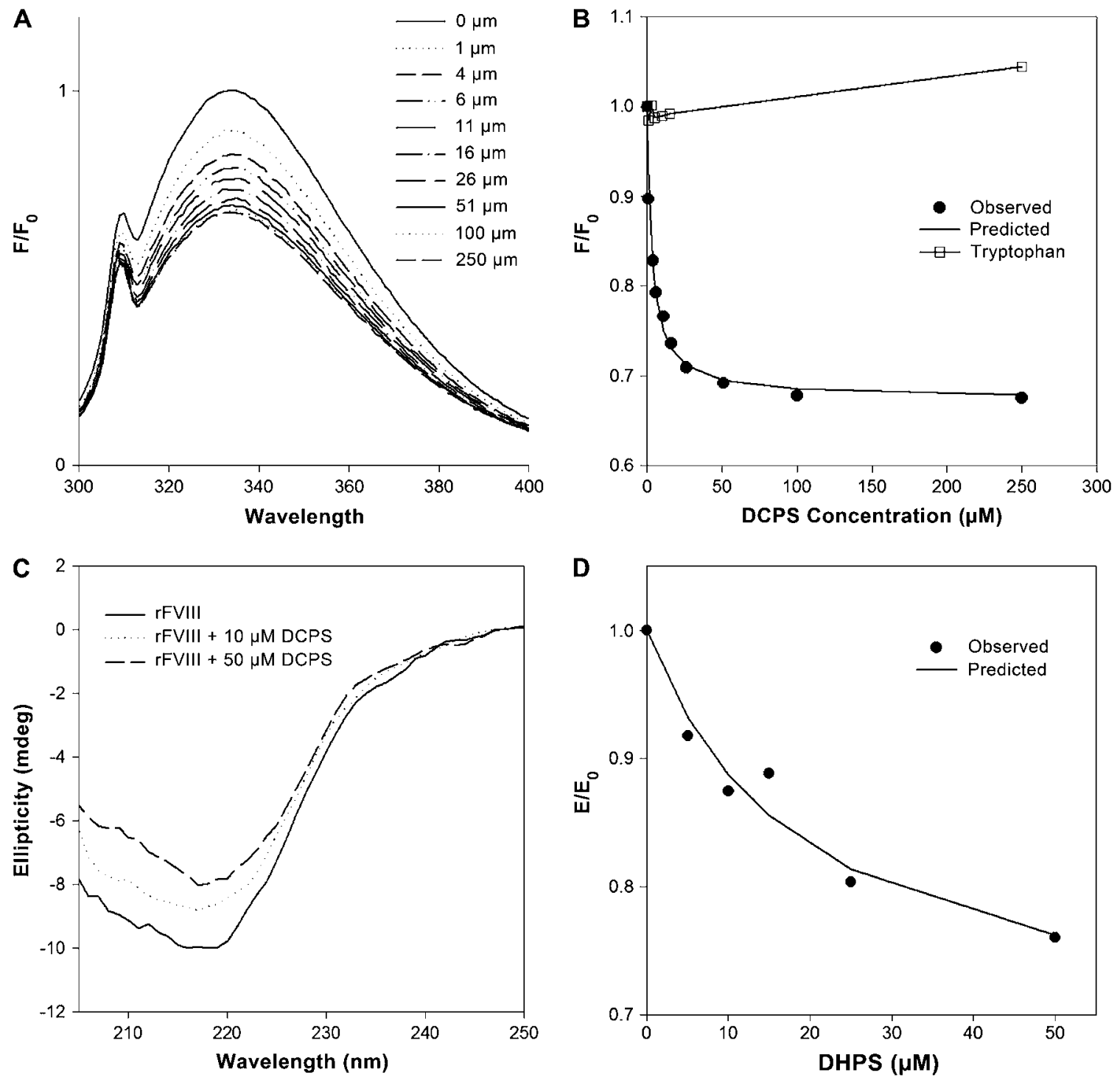

Figure 2. Effect of DCPS on structure of rFVIII. (a) Changes in the emission spectra of rFVIII as a function of DCPS concentration. The sample was excited at $285 \mathrm{~nm}$, and the emission spectra were obtained from 300 to $400 \mathrm{~nm}$. (b) Changes in the intrinsic fluorescence $\left(\mathrm{F} / \mathrm{F}_{\mathrm{o}}\right)$ of $\mathrm{rFVIII}$ and tryptophan as a function of DCPS concentration. The excitation was set at $285 \mathrm{~nm}$, and emission was monitored at $335 \mathrm{~nm}$ with a $4-\mathrm{nm}$ slit width. The protein concentration typically used was $0.017 \mu \mathrm{M}$. Tryptophan was used at a concentration of $0.6 \mu \mathrm{M}$. Raw data for rFVIII were fitted using Equation 1 to obtain estimates for the binding parameters. (c) Changes in the far UV-CD spectra of rFVIII obtained from 205 to $250 \mathrm{~nm}$ as a function of DCPS concentration. (d) Changes in the ellipticity $\left(\mathrm{E} / \mathrm{E}_{\mathrm{o}}\right)$ at $215 \mathrm{~nm}$ for $\mathrm{rFVIII}$ as a function of DCPS concentration. The protein concentration typically used was $0.064 \mu \mathrm{M}$ in a $1-\mathrm{cm}$ pathlength cuvette. Raw data were fitted using Equation 1 to obtain estimates for the binding parameters. DCPS indicates dicaproyl phosphatidylserine; rFVIII, recombinant factor VIII; CD, circular dichroism.

subtle changes in the secondary structure of the protein. The data were fit into Equation 1, and the apparent $\mathrm{K}_{\mathrm{D}}$ was estimated to be $19.2 \mu \mathrm{M}( \pm \mathrm{SE}, 6.98)$ with a maximal change of $\sim 33 \%$. The $\mathrm{K}_{\mathrm{D}}$ estimated with $\mathrm{CD}$ spectroscopy studies appears to be higher than that estimated with fluorescence spectroscopy. This discrepancy is probably caused by a difference in the structural aspects of the protein being monitored by the respective techniques. The estimated $K_{D}$ is hence a phenomenological $\mathrm{K}_{\mathrm{D}}$ and is representative of the changes occurring in only the structural component being monitored.

\section{Sandwich ELISA-Interaction of DCPS With rFVIII}

ESH4, a monoclonal antibody, binds to the phospholipid binding region of $\mathrm{rFVIII}$. Binding of DCPS to this region would compete with ESH4 binding, resulting in a lower ELISA response. As can be seen from Figure 3a, increasing concentrations of DCPS caused a decrease in the binding of rFVIII to ESH4, and this decrease was observed for concentrations both above and below the CMC. This indicates that both the soluble and the micellar forms of DCPS can interact with the phospholipid binding region of rFVIII. As 

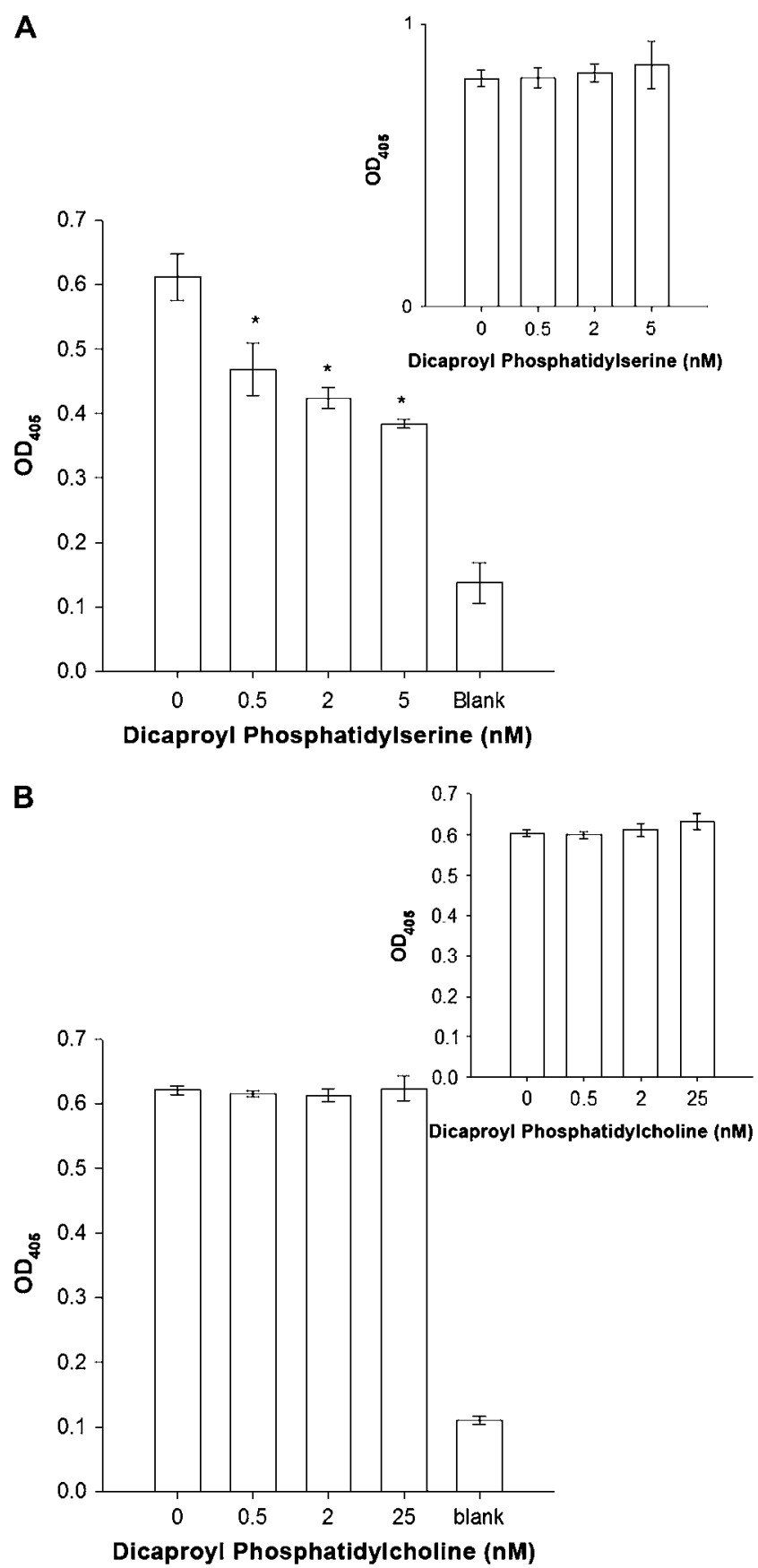

Figure 3. Binding of DCPS to the phospholipid binding region: effect of (a) DCPS and (b) DCPC on the binding of rFVIII to ESH4 as determined by sandwich enzyme-linked immunosorbent assay. Insets: effect of preincubation of DCPS and DCPC on the binding of rFVIII with ESH4. Statistical analysis: analysis of variance followed by post hoc Dunnett test $(*, P<.05)$. DCPS indicates dicaproyl phosphatidylserine; DCPC, dicaproyl phosphatidylcholine; rFVIII, recombinant factor VIII.

DCPS has detergent-like properties, an additional control experiment was conducted in which DCPS alone was incubated with ESH4-coated wells before the addition of rFVIII. As can be seen from the inset of Figure 3a, the optical densities were independent of the concentration of DCPS, which rules out the possibility of stripping of the immobilized
ESH4 by DCPS. Hence, the observed reduction in rFVIII binding to ESH4 in the presence of DCPS is mainly due to competition between ESH4 and DCPS for binding to the phospholipid binding region of rFVIII.

The interaction of DCPC to the phospholipid binding region was also investigated in the sandwich ELISA at concentrations above and below the CMC. As can be seen in Figure $3 \mathrm{~b}, \mathrm{DCPC}$ did not interfere with the binding of rFVIII to ESH4. This suggests that DCPC does not interact with the phospholipid binding region of $\mathrm{rFVIII}$ and the interaction of DCPS with $\mathrm{rFVIII}$ is specific.

\section{Effect of DCPS on Thermal Denaturation of rFVIII}

Our previous studies have shown that rFVIII aggregation may at least in part be initiated by conformational changes in the phospholipid binding region in the $\mathrm{C} 2$ domain of rFVIII. ${ }^{35}$ Because DCPS binds to the phospholipid binding region, we determined the effect of DCPS on the aggregation behavior of rFVIII using CD under thermal denaturing conditions. Thermal stress was chosen to investigate the effects of DCPS, as it is frequently used to understand protein folding and stability issues. ${ }^{36}$

The thermal unfolding of $\mathrm{rFVIII}$ at a heating rate of $60^{\circ} \mathrm{C} / \mathrm{hr}$ in the presence and absence of DCPS was monitored at $215 \mathrm{~nm}$ using far UV-CD spectroscopy. As can be seen for rFVIII (Figure 4, inset), there was no significant change in

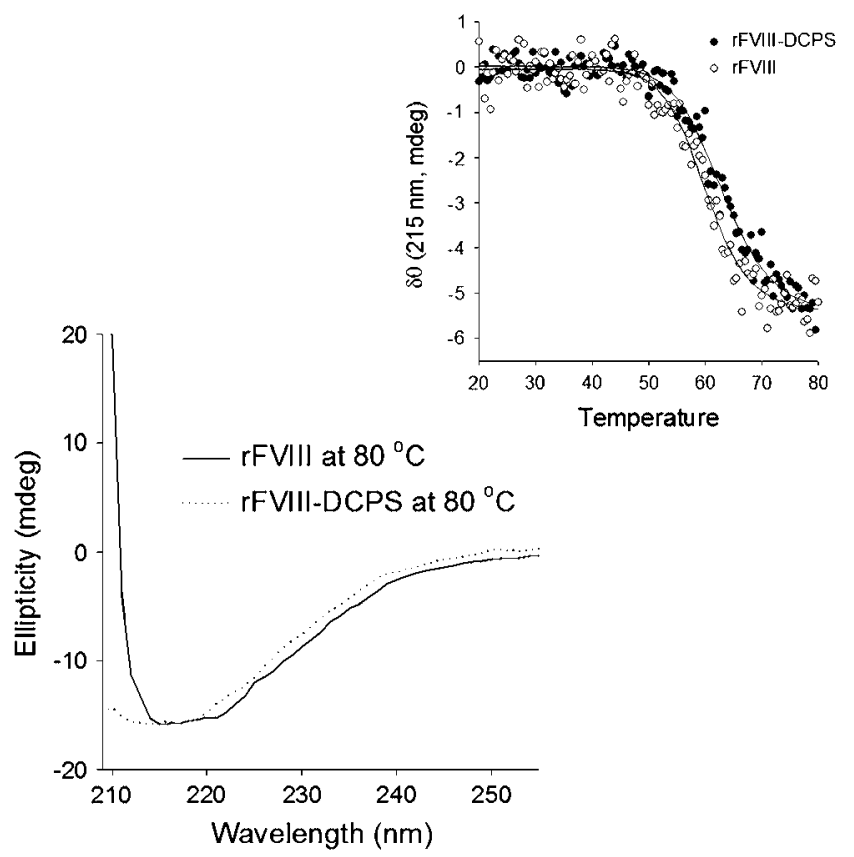

Figure 4. Effect of DCPS on thermal denaturation of rFVIII: far UV-CD spectra of rFVIII and rFVIII-DCPS after heating to $80^{\circ} \mathrm{C}$. Inset: Thermal unfolding profiles of $\mathrm{rFVIII}$ in the presence $(\bullet)$ and absence (०) of DCPS. The protein concentration was $\sim 20$ $\mu \mathrm{g} / \mathrm{mL}$, and DCPS was used at a concentration of $0.05 \mathrm{mM}$.

DCPS indicates dicaproyl phosphatidylserine; rFVIII, recombinant factor VIII; $\mathrm{CD}$, circular dichroism. 
the ellipticity values over the temperature range of $20^{\circ} \mathrm{C}$ to $45^{\circ} \mathrm{C}$. Beyond $50^{\circ} \mathrm{C}$ an increase in negative ellipticity was observed. The midpoint of the transition as determined by fitting to Equation 2 was $\sim 60^{\circ} \mathrm{C}$. In the presence of DCPS, a similar profile was obtained, suggesting that the intrinsic stability of rFVIII was unaltered.

Far UV-CD spectra were also acquired at various temperatures along the thermal unfolding profile of rFVIII in the presence and absence of DCPS. The far UV-CD spectrum of rFVIII (Figure 2c) acquired at $20^{\circ} \mathrm{C}$ showed a broad negative band at $215 \mathrm{~nm}$, suggesting that the protein exists predominantly in a $\beta$-sheet conformation. At elevated temperatures the spectrum showed (Figure 4) a bathochromic shift in the negative band at $215 \mathrm{~nm}$ with a positive band beyond $210 \mathrm{~nm}$, indicating the formation of aggregates stabilized by intermolecular $\beta$-strands. ${ }^{35}$ However, in the presence of DCPS the far UV-CD spectral features characteristic of intermolecular $\beta$-strands were not observed (Figure 4), indicating that DCPS interfered with the aggregation of the protein by preventing conformational transitions necessary for the formation of intermolecular $\beta$-strands.

\section{Immunogenicity of rFVIII-DCPS Complex}

DCPS interacts with the C2 domain of rFVIII, which encompasses several immunodominant epitopes. ${ }^{21,22}$ Hence, we tested the hypothesis that administration of rFVIII complexed to DCPS could reduce the overall immunogenicity of $\mathrm{rFVIII}$ in hemophilia A mice. The hemophilia A mice have enabled investigations of the immune responses against rFVIII, as the immune response observed in this animal model has been shown to be qualitatively similar to that observed in humans. ${ }^{30,37}$ Additionally, the murine hemophilia A model has been employed to test strategies that could reduce the immunogenicity of rFVIII. ${ }^{38,39}$ Immunogenicity studies were conducted following subcutaneous administration of the protein to amplify the immune response for meaningful comparison. The total antibody titers and inhibitory titers in immunized mice were determined by antibody capture ELISA and NMB assay (Figure 5).

rFVIII-DCPS complexes were prepared at DCPS concentrations below the $\mathrm{CMC}$, and their immunogenicity was compared with rFVIII's. The total antibody titers for animals given rFVIII with soluble DCPS below CMC (rFVIIIDCPS $_{\text {sol }}$ ) and rFVIII alone are shown in Figure 5a. Animals given rFVIII-DCPS ${ }_{\text {sol }}$ had slightly lower total antibody titers $(9.40 \mathrm{E}+03 \pm 1.89 \mathrm{E}+03, \pm \mathrm{SEM}, \mathrm{n}=12)$ relative to animals given $r F V I I I$ alone $(1.32 \mathrm{E}+04 \pm 2.04 \mathrm{E}+03, \pm \mathrm{SEM}$, $\mathrm{n}=15$ ). A similar pattern (Figure $5 \mathrm{~b}$ ) was also observed for the inhibitory titers: animals administered rFVIII-DCPS ${ }_{\text {sol }}$ had lower inhibitory titers $(5.01 \mathrm{E}+02 \pm 104 \mathrm{BU} / \mathrm{mL}, \pm$ SEM, $\mathrm{n}=9)$ relative to animals given $\mathrm{rFVIII}$ alone $(6.90 \mathrm{E}+02 \pm 78.1 \mathrm{BU} / \mathrm{mL}, \pm \mathrm{SEM}, \mathrm{n}=13)$. Although the
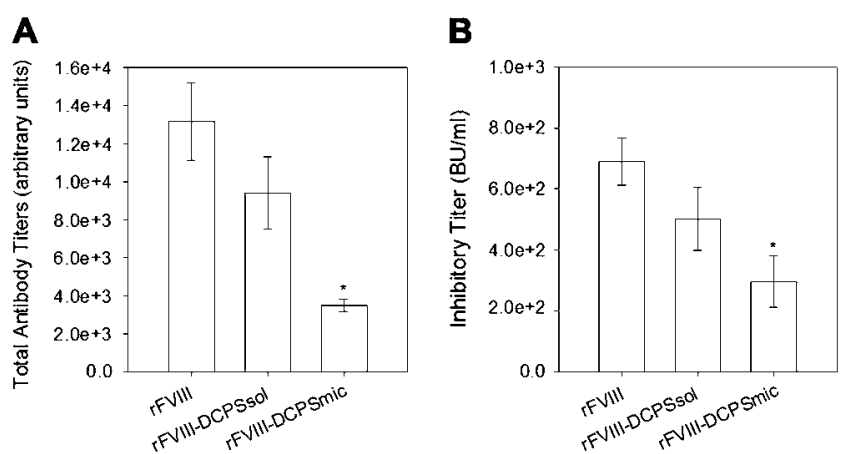

Figure 5. Effect of DCPS on the immunogenicity of rFVIII: (a) total mean antibody titers against rFVIII as determined by antibody capture enzyme-linked immunosorbent assay; and (b) inhibitory antibody titers as determined by Nijmegen modification of the Bethesda assay at 6 weeks in hemophilia A mice immunized with rFVIII, rFVIII-DCPS ${ }_{\text {sol }}$, or rFVIII$\mathrm{DCPS}_{\text {mic }}$. Error bars, \pm SEM. Statistical analysis: analysis of variance followed by post hoc Dunnett test $(*, P<.05)$. DCPS indicates dicaproyl phosphatidylserine; rFVIII, recombinant factor VIII; BU, Bethesda unit.

total and inhibitory titers for rFVIII-DCPS sol $_{\text {were lower }}$ than those observed for rFVIII, statistical significance could not be achieved. We also evaluated the effect of DCPC $\left(\mathrm{rFVIII-DCPC} \mathrm{sol}_{\mathrm{si}}\right)$ on the immunogenicity of $\mathrm{rFVIII}$ as a control. Animals given rFVIII-DCPC ${ }_{\text {sol }}$ had mean total $(9.62 \mathrm{E}+03 \pm 1.20 \mathrm{E}+03 \mathrm{BU} / \mathrm{mL}, \pm \mathrm{SEM}, \mathrm{n}=12)$ and inhibitory $(5.63 \mathrm{E}+02 \pm 119 \mathrm{BU} / \mathrm{mL}, \pm \mathrm{SEM}, \mathrm{n}=8)$ antibody titers slightly higher than those observed for rFVIII-DCPS ${ }_{\text {sol }}$, although statistical significance was not achieved. This may suggest that only DCPS is lowering the immunogenicity of rFVIII at concentrations below CMC.

We also investigated the effects of DCPS on the immunogenicity of rFVIII at concentrations $(5 \mathrm{mM})$ where DCPS would exist as micelles (rFVIII-DCPS ${ }_{\text {mic }}$ ). As can be seen in Figure 5, animals given $\mathrm{rFVIII-DCPS} \mathrm{mic}_{\text {ic }}$ had significantly lower total $(3.51 \mathrm{E} \pm 03 \pm 332, \pm \mathrm{SEM}, \mathrm{n}=12, P<.05)$ and inhibitory $(295 \pm 84.0 \mathrm{BU} / \mathrm{mL}, \pm \mathrm{SEM}, \mathrm{n}=8, P<.05)$ antibody titers relative to animals given $\mathrm{rFVIII}$ alone. This suggests that the micellar form of DCPS reduced the immune response against $r F V I I I$.

The reason for the lower immune response observed for rFVIII complexed to micellar forms of the DCPS is not clear. However, we believe that processing of rFVIII by the immune system in the presence of DCPS micelles is inefficient. The inefficient processing can in turn lead to reduced stimulation of the T helper cells, B cells, and concomitant cytokine (IL-10) production that is necessary for sustaining a humoral immune response.

\section{CONCLUSION}

Overall, our findings suggest that short-chain phospholipids such as DCPS may be promising excipients for reducing the 


\section{The AAPS Journal 2006; 8 (2) Article 41 (http://www.aapsj.org).}

immunogenicity of rFVIII and warrant further investigation. The above results further confirm our previous observations, which had suggested that molecules and molecular assemblies capable of interacting with the lipid binding region of rFVIII may be useful multifunctional excipients for rFVIII. ${ }^{24,35}$

\section{ACKNOWLEDGMENTS}

The authors thank the Pharmaceutical Sciences Instrumentation Facility, University at Buffalo, for the use of the circular dichroism spectropolarimeter and spectrofluorometer. This work was supported by the National Heart, Lung, and Blood Institute, National Institutes of Health grant R01 HL-70227 to S.V.B.

\section{REFERENCES}

1. Foster PA, Zimmerman TS. Factor VIII structure and function. Blood Rev. 1989;3:180-191.

2. Lenting PJ, van Mourik JA, Mertens K. The life cycle of coagulation factor VIII in view of its structure and function. Blood. 1998;92:3983-3996.

3. Toole JJ, Knopf JL, Wozney JM, et al. Molecular cloning of a cDNA encoding human antihaemophilic factor. Nature. 1984;312:342-347.

4. Kaufman RJ, Wasley LC, Dorner AJ. Synthesis, processing, and secretion of recombinant human factor VIII expressed in mammalian cells. J Biol Chem. 1988;263:6352-6362.

5. Vehar GA, Keyt B, Eaton D, et al. Structure of human factor VIII. Nature. 1984;312:337-342.

6. Fay PJ. Reconstitution of human factor VIII from isolated subunits. Arch Biochem Biophys. 1988;262:525-531.

7. Wise RJ, Dorner AJ, Krane M, Pittman DD, Kaufman RJ. The role of von Willebrand factor multimers and propeptide cleavage in binding and stabilization of factor VIII. J Biol Chem. 1991;266:21948-21955.

8. Weiss HJ, Sussman II, Hoyer LW. Stabilization of factor VIII in plasma by the von Willebrand factor. Studies on posttransfusion and dissociated factor VIII and in patients with von Willebrand's disease. J Clin Invest. 1977;60:390-404.

9. Kaufman RJ, Dorner AJ, Fass DN. von Willebrand factor elevates plasma factor VIII without induction of factor VIII messenger RNA in the liver. Blood. 1999;93:193-197.

10. Bolton-Maggs PH, Pasi KJ. Haemophilias A and B. Lancet. 2003;361:1801-1809.

11. Manco-Johnson M. Hemophilia management: optimizing treatment based on patient needs. Curr Opin Pediatr. 2005;17:3-6.

12. Ananyeva NM, Lacroix-Desmazes S, Hauser CA, et al. Inhibitors in hemophilia A: mechanisms of inhibition, management and perspectives. Blood Coagul Fibrinolysis. 2004;15:109-124.

13. Oldenburg J, Schroder J, Hermann Brackmann H, Muller-Reible C, Schwaab R, Tuddenham E. Environmental and genetic factors influencing inhibitor development. Semin Hematol. 2004;41:82-88.

14. Saint-Remy JM, Lacroix-Desmazes S, Oldenburg J. Inhibitors in haemophilia: pathophysiology. Haemophilia. 2004;10:146-151.

15. Roberts HR, Monroe DM, White GC. The use of recombinant factor VIIa in the treatment of bleeding disorders. Blood.

2004; 104:3858-3864.
16. Ingerslev J. Hemophilia. Strategies for the treatment of inhibitor patients. Haematologica. 2000;85:15-20.

17. Ho AY, Height SE, Smith MP. Immune tolerance therapy for haemophilia. Drugs. 2000;60:547-554.

18. Gensana M, Altisent C, Aznar JA, et al. Influence of von Willebrand factor on the reactivity of human factor VIII inhibitors with factor VIII. Haemophilia. 2001;7:369-374.

19. Lollar P, Healey JF, Barrow RT, Parker ET. Factor VIII inhibitors. Adv Exp Med Biol. 2001;489:65-73.

20. Reding MT, Okita DK, Diethelm-Okita BM, Anderson TA, ContiFine BM. Epitope repertoire of human CD4(+) T cells on the A3 domain of coagulation factor VIII. $J$ Thromb Haemost. 2004;2:1385-1394.

21. Reding MT, Okita DK, Diethelm-Okita BM, Anderson TA, Conti-Fine BM. Human CD4+ T-cell epitope repertoire on the C2 domain of coagulation factor VIII. J Thromb Haemost. 2003;1: 1777-1784.

22. Pratt KP, Qian J, Ellaban E, et al. Immunodominant T-cell epitopes in the factor VIII C2 domain are located within an inhibitory antibody binding site. Thromb Haemost. 2004;92:522-528.

23. Raju R, Navaneetham D, Okita D, Diethelm-Okita B, McCormick D, Conti-Fine BM. Epitopes for human CD4+ cells on diphtheria toxin: structural features of sequence segments forming epitopes recognized by most subjects. Eur J Immunol. 1995;25:3207-3214.

24. Purohit VS, Jr, Ramani K, Jr, Sarkar R, Jr, Kazazian HH, Jr, Balasubramanian SV. Lower inhibitor development in hemophilia A mice following administration of recombinant factor VIII-O-phosphoL-serine complex. J Biol Chem. 2005;280:17593-17600.

25. Balasubramanian V, Ramanathan M. Glycosaminoglycans alter the conformation of interferon-gamma. Cytokine. 2000;12:466-471.

26. Hauser H. Short-chain phospholipids as detergents. Biochim Biophys Acta. 2000;1508:164-181.

27. Derrick TS, Kashi RS, Durrani M, Jhingan A, Middaugh CR. Effect of metal cations on the conformation and inactivation of recombinant human factor VIII. J Pharm Sci. 2004;93:2549-2557.

28. Ramani K, Purohit V, Middaugh CR, Balasubramanian SV. Aggregation kinetics of recombinant human FVIII (rFVIII). J Pharm Sci. 2005;94:2023-2029.

29. Bi L, Jr, Lawler AM, Jr, Antonarakis SE, Jr, High KA, Jr, Gearhart JD, Jr, Kazazian HH, Jr. Targeted disruption of the mouse factor VIII gene produces a model of haemophilia A. Nat Genet. 1995;10:119-121.

30. Qian J, Jr, Borovok M, Jr, Bi L, Jr, Kazazian HH, Jr, Hoyer LW. Inhibitor antibody development and $\mathrm{T}$ cell response to human factor VIII in murine hemophilia A. Thromb Haemost. 1999;81:240-244.

31. Chattopadhyay A, London E. Fluorimetric determination of critical micelle concentration avoiding interference from detergent charge. Anal Biochem. 1984;139:408-412.

32. Zarif L. Drug delivery by lipid cochleates. Methods Enzymol. 2005;391:314-329.

33. Ramani K, Balasubramanian SV. Fluorescence properties of Laurdan in cochleate phases. Biochim Biophys Acta. 2003;1618: 67-78.

34. Zhai X, Srivastava A, Drummond DC, Daleke D, Lentz BR. Phosphatidylserine binding alters the conformation and specifically enhances the cofactor activity of bovine factor Va. Biochemistry. 2002;41:5675-5684.

35. Ramani K, Purohit VS, Miclea RD, Middaugh CR, Balasubramanian SV. Lipid binding region (2303-2332) is involved in 


\section{The AAPS Journal 2006; 8 (2) Article 41 (http://www.aapsj.org).}

aggregation of recombinant human FVIII (rFVIII). J Pharm Sci. 2005;94:1288-1299.

36. Tsai PK, Volkin DB, Dabora JM, et al. Formulation design of acidic fibroblast growth factor. Pharm Res. 1993;10:649-659.

37. Reipert BM, Ahmad RU, Turecek PL, Schwarz HP. Characterization of antibodies induced by human factor VIII in a murine knockout model of hemophilia A. Thromb Haemost. 2000;84:826-832.
38. Qian J, Collins M, Sharpe AH, Hoyer LW. Prevention and treatment of factor VIII inhibitors in murine hemophilia A. Blood. 2000;95:1324-1329.

39. Behrmann M, Pasi J, Saint-Remy JM, Kotitschke R, Kloft M. Von Willebrand factor modulates factor VIII immunogenicity: comparative study of different factor VIII concentrates in a haemophilia A mouse model. Thromb Haemost. 2002;88:221-229. 